\title{
Which water for alendronate administration?
}

\author{
R. Pellegrini
}

Received: 30 August 2008 / Accepted: 13 October 2008 / Published online: 28 October 2008

(C) International Osteoporosis Foundation and National Osteoporosis Foundation 2008

\section{Dear Editors,}

Very likely some clinical trials on alendronate in tablets, taken with tap water (the possibility of using distilled water was not envisaged), do not report the real activity of the product, for the following reasons.

In the Physician's Desk Reference [1], it is stated that Fosamax must be taken with tap water only and not with mineral water (the word "not" is printed in bold type) since other beverages, including mineral water, are likely to reduce its absorption by as much as $60 \%$ due to their content of calcium and other cations [2,3].

The package insert of Fosamax in Italy, but most probably not only in Italy, has integrally reproduced this statement, saying that the product "must be taken with tap water only and not with mineral water."

The most authoritative Martindale [4] writes that "absorption is decreased by food, especially by products containing calcium or other polyvalent cations". These other cations are, however, not specified, thus implying that calcium is the main negative substance, an assumption confirmed further on where it writes that "mineral water with a high concentration of calcium should be avoided" without mentioning other unfavourable water components.

Now, the aforementioned formulation of the package insert is practically a nonsense, owing to the well-known huge differences among waters, both tap and mineral, as to

R. Pellegrini $(\bowtie)$

Medical Semeiotics, University of Bologna,

Bologna, Italy

e-mail: rinaldo19@interfree.it

R. Pellegrini

Piazzale Marengo 6,

20121 Milan, Italy their mineral content. For example, while in some areas of Italy the calcium content of tap water is rather low, in other areas, e.g. in Rome and in some parts of Milan, it is significantly high, namely $100-110 \mathrm{mg} / \mathrm{l}$, which means up to 100 times higher than that in some commercially available bottled waters with a calcium content of 1 or $2 \mathrm{mg} / \mathrm{l}$. And practically nobody knows what they are drinking when a tap water is used, while all bottles of mineral water are by law (at least in Italy) labelled with the specification of all the single components.

The conclusion is that, following the instructions of the package inserts of all the products containing alendronate, many patients may miss up to $60 \%$ of its therapeutic activity, damaging not only their health but also their finances. And, while waiting for improbable amendments from the pharmaceutical companies and/or the regulatory authorities, it would be wise to follow Azoulay et al. [5] who conclude:“ physicians should encourage patients to check the mineral content of their drinking water, whether tap or bottled, and choose water most appropriate for their needs".

\section{References}

1. Physician's Desk Reference (2008) Fosamax. Thomson Healthcare, Montvale, NJ

2. Gertz BJ, Holland SD, Kline WF et al (1995) Studies of the oral bioavailability of alendronate. Clin Pharmacol Ther 58:288-298

3. Porras AG, Holland SD, Gertz BJ (1999) Pharmacokinetics of alendronate. Clin Pharmacokinet 36:315-328

4. Sweetman SC (ed ) (2007) Martindale, the complete drug reference. Pharmaceutical Press, London

5. Azoulay A, Garzon P, Eisenberg MJ (2001) Comparison of the mineral content of tap water and bottled waters. J Gen Intern Med $16: 168-175$ 